\title{
Differences in leukocyte profile, gene expression, and metabolite status of dairy cows with or without sole ulcers
}

\author{
Keelin O'Driscoll, ${ }^{1}$ Matthew McCabe, and Bernadette Earley \\ Animal and Bioscience Research Department, Animal and Grassland Research and Innovation Centre, Teagasc, Dunsany, Co. Meath, Ireland
}

\begin{abstract}
Sole ulcers are one of the most severe pathologies causing lameness in dairy cows and are associated with abnormal behavior and impaired production performance. However, little is known about how or whether lameness caused by sole ulcers affects the cow systemically. This study compared hematology profile, leukocyte gene expression, and physiological responses [metabolite, cortisol, the endogenous steroid hormone dehydroepiandrosterone (DHEA), and haptoglobin concentrations] of cows with sole ulcers and healthy cows. Twelve clinically lame cows (lame) were identified as having at least one sole ulcer and no other disorder, and matched with a cow that had good locomotion and no disorders (sound), using days in milk, liveweight, body condition score, and diet. Blood samples were taken from all 24 cows within $24 \mathrm{~h}$ of sole ulcer diagnosis. Leukocyte counts were obtained using an automated cell counter, cortisol and DHEA concentration by ELISA, and plasma haptoglobin, urea, total protein, creatine kinase, and glucose were analyzed on an Olympus analyzer. Expression of 16 genes associated with lameness or stress were estimated using reverse transcription-PCR. Data were analyzed using the MIXED procedure in SAS software (version 9.3; SAS Institute Inc., Cary, NC). Lame cows had a higher neutrophil percentage, a numerically lower lymphocyte percentage, and tended to have a higher neutrophil:lymphocyte ratio than sound cows. Serum cortisol and DHEA concentrations were higher in lame than in sound cows. Lame cows also tended to have higher haptoglobin and glucose levels than sound, as well as higher protein yet lower urea levels. Sound cows tended to have higher relative expression of the gene coding for colony-stimulating factor 2 than lame, but in all other cases where differences were detected in cytokine gene expression $(I L-1 \alpha, I L-1 \beta, C X C L 8$, and $I L-10)$, relative gene expression in sound cows tended to be, or was, lower than in lame. Relative expression
\end{abstract}

Received April 2, 2014.

Accepted November 20, 2014.

${ }^{1}$ Corresponding author: keelin.odriscoll@teagasc.ie of MMP-13, GR- $\alpha$, Fas, haptoglobin, and CD62L were, or tended to be, higher in lame than sound cows. A high neutrophil:lymphocyte ratio in combination with higher cortisol levels in cows with ulcers is indicative of physiological stress. Moreover, increased DHEA and a higher cortisol:DHEA ratio, as well as a tendency for higher haptoglobin levels and increased haptoglobin mRNA expression, are indicative of systemic inflammation. Increased cytokine mRNA expression indicates activation of the immune system compared with healthy cows. Increased expression of MMP-13 mRNA has been found in cows with impaired locomotion and thus could be implicated in development of claw horn disorders.

Key words: lameness, sole ulcer, immune, gene expression, stress

\section{INTRODUCTION}

Lameness is the most serious welfare problem facing the dairy cow and the European dairy industry (EFSA, 2009). The disorder causes pain and distress for the cow (Whay et al., 2003) and substantial economic losses (Kossaibati and Esslemont, 1997). Sole ulcers, which are one of the most severe pathologies causing lameness, are noninfectious in nature and occur when claw horn formation is disrupted. The underlying tissue then becomes inflamed and sometimes exposed (Murray et al., 1996). Cows are particularly vulnerable around the time of parturition; changes in hormone levels cause increased vascular permeability, increasing the risk of edema and ischemia in the hoof (Nocek, 1997; Tarlton et al., 2002; Knott et al., 2007), while concurrent weakening of connective tissue causes the pedal bone to drop and compress the corium, further disrupting claw horn formation (Thoefner et al., 2005).

Lameness is associated with behavioral and physiological changes indicative of a sickness response (Whay et al., 1997; Almeida et al., 2008), which facilitates host survival during illness and tissue injury (Hart, 1988). The sickness response is regulated by immune-to-brain communication initiated by pro-inflammatory cytokines released by activated immune cells (Watkins and Maier, 1999). Thus, lameness likely causes systemic activation of the immune system. 
Using a microarray-based gene expression profiling of peripheral blood mononuclear cells, Almeida et al. (2007) identified a small number of genes that the authors hypothesized could be differentially expressed specifically as a response to lameness. However, use of a whole leukocyte population approach, rather than focusing on particular cell types, could provide a broader picture of immunological interactions (Bleavins et al., 2011). Immune system genes are often expressed by more than one leukocyte cell type, and thus their overall expression level in response to lameness could be more accurately represented by examining combined leukocyte populations.

As well as differences in gene expression, several other physiological responses could be expected as a response to lameness. For instance, Almeida et al. (2008) found that lame cows had a tendency for higher serum cortisol levels, but lower dehydroepiandrosterone (DHEA) levels, compared with healthy cows. They also had a higher cortisol:DHEA ratio, which is often used as an indicator of inflammation. Moreover the acute phase protein, haptoglobin, is elevated in lame cows (Jawor et al., 2008; Tadich et al., 2013), which in turn could drive up total serum protein levels (Jawor et al., 2008). Contrarily, serum urea is lower in sheep and beef cattle that have been exposed to acute stressors (Galyean et al., 1981; Apple et al., 1993). Other variables that could be possibly be influenced by the presence of lameness include creatine kinase and glucose. Creatine kinase is associated with tissue breakdown, whereas glucose levels can be raised in response to a tissue injury (Weissman, 1990).

Neutrophils are phagocytic granulocytes of the innate immune system that respond to glucocorticoids (Weber et al., 2006). Because lame cows have higher cortisol levels than sound cows, it is possible that lame animals could experience neutrophilia, as well as altered expression of genes associated with apoptosis and inflammation (Burton et al., 2005).

As yet, the majority of studies that have investigated physiological and immune parameters in relation to lameness have simply compared lame and healthy cows, without considering the cause of the lameness. The objective of this study was to characterize the leukocyte profile, leukocyte gene expression, cortisol and DHEA response, and aspects of the metabolite profile of cows that have a single lameness-causing pathology, sole ulcers, and compare these with healthy cows. We hypothesized that cows with sole ulcers would show differences from healthy cows in all variables. The information generated will provide more insight into the systemic effects of lameness caused by sole ulcers.

\section{MATERIALS AND METHODS}

The study animals were located at the Moorepark research farms, part of the Animal and Grassland Research and Innovation Centre, Teagasc, Moorepark, Fermoy, Co. Cork, Ireland. Blood samples were collected between November 2010 and October 2011, and analysis carried out at the Animal and Bioscience Research Department, Animal and Grassland Research and Innovation Centre, Teagasc, Grange, Dunsany, Co. Meath, Ireland.

\section{Animals and Treatments}

All animal procedures performed in this study were conducted under experimental license (B100/4319) from the Irish Department of Health and Children in accordance with the Cruelty to Animals Act 1876 and the European Communities (Amendment of Cruelty to Animals Act 1876) Regulation 2002 and 2005. The study subjects consisted of 24 lactating HolsteinFriesian cows. Twelve cows were clinically lame due to the presence of one or more sole ulcers, but otherwise healthy with no other foot disorders. Each lame animal was paired with a healthy cow.

\section{Locomotion and Hoof Scoring}

All cows from the herd were observed individually walking from the milking parlor once per week, on a clean grooved concrete floor. Cows that were clinically lame (obvious impairment of one or more limbs when moving forward) were selected for locomotion and hoof scoring the following morning. Locomotion and hoof scoring was carried out by the same person throughout the trial.

Cow locomotory ability was determined after morning milking as cows walked along a clean concrete track away from the milking parlor. They were observed from the side as they walked past, and then from behind. Five aspects of locomotion were scored (spine curvature, tracking up, ab/adduction, speed, and head bob) using the system adopted by O'Driscoll et al. (2010). Each of the 5 aspects were scored from 1 (perfect) to 5 (extremely impaired). These 5 aspects were summed to give one overall locomotion score per cow. Thus, the minimum score was 5 (perfect locomotion), and the maximum was 25 (extreme clinical lameness, cow virtually immobile).

Cows were restrained in a metal crate, their hind feet lifted, and the claws individually examined. The hind claws were cleaned and a sliver of horn was trimmed 
using a quittor knife (Hauptner Quittor Hoof Knife, Channelle Vet Products, Loughrea, Ireland) from the entire area of the weight-bearing surface to expose fresh horn. Hooves were examined for the presence of sole lesions, heel erosion, digital dermatitis, and white line disease (as described by O'Driscoll et al., 2008), as well as sole ulcers. Only cows that had no other disorder besides sole ulcers were included in the lame cohort.

Once a lame cow was identified for inclusion in the study, a sound partner was selected from the herd. Using herd list details, a shortlist of possible partner cows that were of a similar lactation number, DIM, liveweight, and BCS was created. The day after identification of the lame cow, these potential partners were locomotion scored, then had their hooves examined, as described previously. Only cows with good locomotion and no hoof pathologies were selected for inclusion as a sound cow. Table 1 shows details of the 12 lame and sound pairs.

\section{Blood Sampling}

Blood samples were collected from each pair of cows by jugular venipuncture before treatment for sole ulcers the day after hoof examination of the sound cow. Blood samples were transported to the laboratory, stored at ambient temperature, and processed within $3.5 \mathrm{~h}$ for hematological analysis, or centrifuged, separated, and stored at $-20^{\circ} \mathrm{C}$ until assays were performed.

\section{Cortisol and DHEA}

Blood collected into a 9-mL serum separator tube (Vacutainer, Unitech Ltd., Dublin, Ireland) was used for measurement of cortisol and DHEA concentrations. Tubes were stored horizontally overnight at $4^{\circ} \mathrm{C}$, then centrifuged at $1,000 \times g$ for $15 \mathrm{~min}$ at $4^{\circ} \mathrm{C}$. Serum was aspirated using a pipette, then stored at $-20^{\circ} \mathrm{C}$ until analysis. Cortisol and DHEA concentrations were measured using an ELISA (Enzo Life Sciences, Sigford Road, Exeter, UK; cortisol = catalog no. ADI-901-071; DHEA = catalog no. ADI-900-093). The sensitivity of the cortisol assay was $56.72 \mathrm{pg} / \mathrm{mL}$, and the intraand interassay CV based on controls were $<10.5$ and $<13.4 \%$, respectively. The sensitivity of the DHEA assay was $2.90 \mathrm{pg} / \mathrm{mL}$, and the intra- and interassay CV based on controls were $<6.4$ and $<8.8 \%$, respectively.

\section{Physiological Variables}

Plasma haptoglobin, urea, total protein, creatine kinase, and glucose were analyzed on an Olympus analyzer (Olympus AU 400, Tokyo, Japan) using reagents supplied by Olympus.

\section{Leukocyte Isolation from Whole Blood}

Thirty-six milliliters of blood collected into acidcitrate-dextrose (ACD) tubes (Vacuette, Cruinn Diagnostics, Dublin, Ireland) from a subset of 8 animals in each cohort was processed within 30 min of collection according to the method of O'Loughlin et al. (2011). Briefly, red blood cells were lysed in a hypotonic solution followed by restoration in $12 \mathrm{~mL}$ of a hypertonic solution. The tubes were then centrifuged to collect the leukocyte pellet, which was washed twice, resuspended in $1 \mathrm{~mL}$ of TRI Reagent (Sigma-Aldrich Ireland Ltd., Dublin, Ireland), pooled by animal, and stored in a sterile tube at $-80^{\circ} \mathrm{C}$ until RNA extractions were performed.

\section{RNA Extraction and cDNA Synthesis}

A modified TRI Reagent extraction method was used to extract total RNA from leukocytes via homogeniza-

Table 1. Details of cows that were clinically lame and had an ulcer (lame) and their partner cow that was healthy (sound)

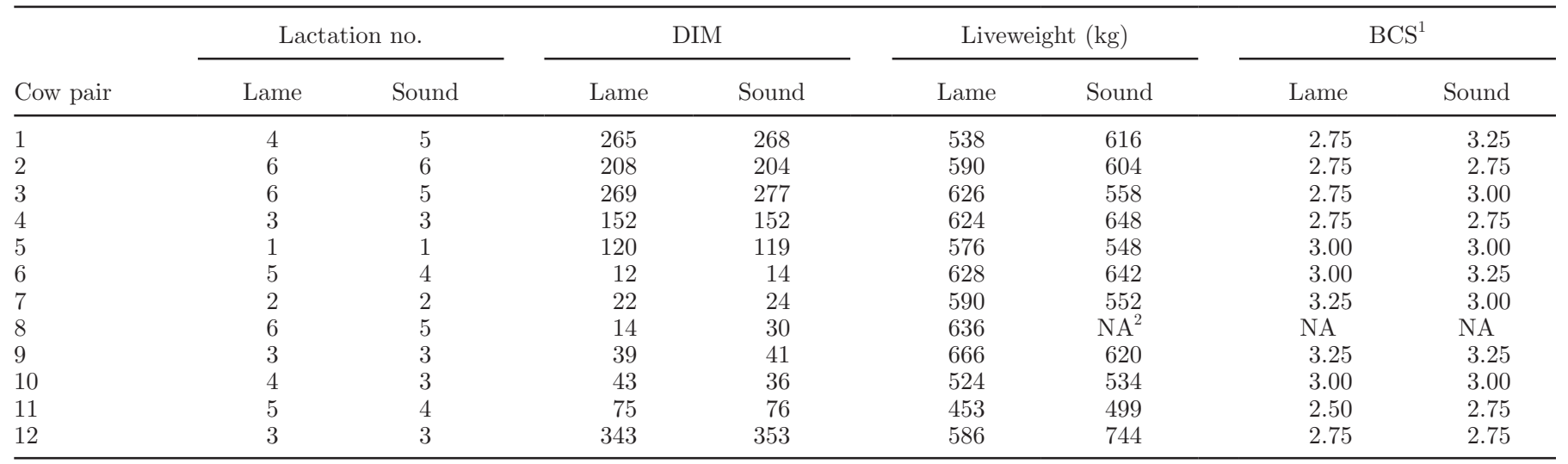

${ }^{1}$ BCS [1 (too thin) to 5 (too fat)].

${ }^{2} \mathrm{NA}=$ not available. 
tion of the pellet in TRI Reagent and the subsequent addition of chloroform followed by precipitation using isopropanol and ethanol. The RNA was quantified using a Nanodrop Spectrophotometer (NanoDrop Technologies, Wilmington, DE). The RNA quality was assessed on an Agilent 2100 Bioanalyser (Agilent Technologies Ireland Ltd., Dublin, Ireland), and only RNA samples with a RNA integrity number of greater than 9.0 were used. Samples were DNase treated and purified using an RNeasy mini kit (Qiagen Ltd., Crawley, UK). One microgram of total RNA per animal was reverse transcribed into cDNA using random hexamers and the High Capacity cDNA Reverse Transcription kit (Applied Biosystems, Dublin, Ireland) in a $20-\mu \mathrm{L}$ reaction and stored at $-20^{\circ} \mathrm{C}$.

\section{Real-Time Reverse-Transcription PCR}

Primers for candidate genes (Table 2) were designed based on bovine sequences obtained from the National Center for Biotechnology Information database using Primer3 software and were commercially synthesized (Sigma-Aldrich Ireland Ltd., Dublin, Ireland). Amplified PCR products were sequenced (Cambridge, UK) and verified with BLAST (http://blast.ncbi.nlm.nih. gov/) to be identical to their respective bovine sequence. Amplification efficiencies were determined for all genes using serial dilutions of pooled cDNA samples. The formula $\mathrm{E}=-1+10(-1 /$ slope $)$, where $\mathrm{E}$ is efficiency, was used where slope refers to the slope of the linear curve of cycle threshold (Cq) values plotted against log dilution. Only primers with PCR efficiencies between 90 and $130 \%$ were used in the current study.

Reference genes used in this study were selected based on previous experience within the research group (O'Loughlin et al., 2011). Three genes were used: $\beta$-actin, succinate dehydrogenase complex subunit A, and GAPDH. These were found to have an average stability value of $\mathrm{M}=0.51$. A normalization factor, calculated based on the geometric mean of the 3 reference genes, was used to normalize the expression of each gene of interest.

Reverse-transcription PCR (RT-qPCR) was performed using the Applied Biosystems 7500 FAST RT-PCR equipment v2.0.1 (Applied Biosystems). One microliter of cDNA was added to a $19 \mu \mathrm{L}$ of master mix which included $10 \mu \mathrm{L}$ of Fast SYBR Green I master mix (Applied Biosystems), $8 \mu \mathrm{L}$ of nuclease-free water, and $0.5 \mu \mathrm{L}$ each of forward and reverse primers at concentrations individually optimized for each primer set. The following RT-qPCR cycle conditions were applied: $95^{\circ} \mathrm{C}$ for $20 \mathrm{~s}$ followed by 40 cycles of $95^{\circ} \mathrm{C}$ for $3 \mathrm{~s}$ and $60^{\circ} \mathrm{C}$ for $30 \mathrm{~s}$, finishing with amplicon dissociation at $95^{\circ} \mathrm{C}$ for $15 \mathrm{~s}, 60^{\circ} \mathrm{C}$ for $1 \mathrm{~min}$, increasing $0.5^{\circ} \mathrm{C}$ per cycle until $95^{\circ} \mathrm{C}$ was reached for $15 \mathrm{~s}$, followed by $60^{\circ} \mathrm{C}$ for $15 \mathrm{~s}$. In accordance with the MIQE guidelines, raw Cq values were imported to GenEx Software v.5.2.2.8 (2010; MultiD Analyses AB, Göteborg, Sweden). Outliers were removed from replicate wells using a modified Grubbs test at a $P<0.05$ confidence interval for any replicate differing from the replicate mean by a standard deviation of more than 0.25 cycles. The $\mathrm{Cq}$ values were adjusted for calculated efficiencies before averaging of replicates. These values were then normalized to the reference genes followed by calculation of relative quantities to the highest $\mathrm{Cq}$ value.

\section{Statistical Analysis}

Statistical analyses were carried out using SAS V9.3 (2002, SAS Institute Inc., Cary, NC), and all data were tested for normality before analysis by examination of box and normal distribution plots, then transformed where necessary. When transformed data were analyzed, least squares means were calculated using raw data to ease clarity of interpretation. Outliers that were outside the 95th percentile were removed.

All data, including locomotion score, were analyzed using the MIXED procedure. The model included fixed effects of cohort (lame or sound), lactation number (1 or greater than 1$)$, and date $(\mathrm{n}=8)$. Weight $(\mathrm{kg})$, DIM, and BCS were included as covariates. Pair was included as a random effect.

When significant effects were found, the Tukey test was used to establish pair-wise differences. Differences were considered significant at $P \leq 0.05$. Tendencies toward significance $(0.05<P \leq 0.10)$ are also presented. Data are presented as least squares means \pm standard error.

\section{RESULTS}

\section{Locomotion Scoring}

Cows in the lame group had higher locomotion scores $(13.5 \pm 0.5)$ than sound cows $(6.7 \pm 0.5 ; P \leq 0.001)$.

\section{Leukocyte Population and Hematological Analysis}

We found no difference between lame and sound cows with regard to total leukocyte number (Table 3). However, lame cows had a higher neutrophil percentage than sound and had a numerically lower lymphocyte percentage. Lame cows also tended to have a higher neutrophil:lymphocyte (N:L) ratio than sound cows. No other differences were observed in leukocyte differential. No difference was observed between lame and sound cows with regard to platelet number, red 
Table 2. Gene, sequence, amplicon size, and National Center for Biotechnology Information (NCBI) accession number of primers used to analyze gene expression by quantitative $\mathrm{PCR}^{1}$

\begin{tabular}{|c|c|c|c|c|c|}
\hline Gene $^{2}$ & $\begin{array}{l}\text { Forward }(\mathrm{F}) \\
\text { or reverse } \\
(\mathrm{R})\end{array}$ & Sequence $5^{\prime} \rightarrow 3^{\prime}$ & $\begin{array}{l}\text { Amplicon } \\
\text { size (bp) }\end{array}$ & $\begin{array}{c}\text { Primer } \\
\text { efficiency } \\
(\%)\end{array}$ & NCBI accession no. \\
\hline \multicolumn{6}{|c|}{ Cytokine gene expression } \\
\hline$I L-1 \alpha$ & $\mathrm{R}$ & CAGCAGCAGCAAACTGAGAC & & & \\
\hline \multirow[t]{2}{*}{$I L-1 \beta$} & $\mathrm{F}$ & CAGTGCCTACGCACATGTCT & 167 & 90 & NM_174093 \\
\hline & $\mathrm{R}$ & CCAGGGATTTTTGCTCTCTG & & & \\
\hline$I L-4$ & $\mathrm{R}$ & CACAGAACAGGTCTTGCTTGCCA & & & \\
\hline \multirow[t]{2}{*}{$C X C L 8$} & $\mathrm{~F}$ & TGGGCCACACTGTGAAAATTC & 92 & 102 & O'Loughlin et al., 2011 \\
\hline & $\mathrm{R}$ & CCTTCTGCACCCACTTTTCC & & & \\
\hline \multirow[t]{2}{*}{$I L-10$} & $\mathrm{~F}$ & ACAGGCTGAGAACCACGGGC & 175 & 105 & NM_174088.1 \\
\hline & $\mathrm{R}$ & GACACCССТCTCTTGGAGCTCACT & & & \\
\hline$C S F-2$ & $\mathrm{~F}$ & CTCCGCACCTACTCGCCCAC & 164 & 109 & NM 174027.2 \\
\hline \multicolumn{6}{|c|}{ General gene expression } \\
\hline \multirow[t]{2}{*}{$M M P-9$} & $\mathrm{~F}$ & CCCGACCCGAGTCGATGCAA & 213 & 109 & NM_174744.2 \\
\hline & $\mathrm{R}$ & GCGGCCACAAGGAACAGGCT & & & \\
\hline \multirow[t]{2}{*}{$M M P-13$} & $\mathrm{~F}$ & CCTCTGGTCTGTTGGCTCACGC & 172 & 101 & NM_174389.2 \\
\hline & $\mathrm{R}$ & GCTCCTGGGTCCTTGGAGTGGT & & & \\
\hline \multirow[t]{2}{*}{$C C R-5$} & $\mathrm{~F}$ & CCCCTACGAGAATCTCTCTCGAGTC & 150 & 93 & NM_001011672.2 \\
\hline & $\mathrm{R}$ & CCAGCGAGTAGAGTGGGGGCA & & & \\
\hline \multirow[t]{2}{*}{$G R-\alpha$} & $\mathrm{F}$ & CCATTTCTGTTCACGGTGTG & 132 & 105 & AY238475 \\
\hline & $\mathrm{R}$ & CTGAACCGACAGGAATTGGT & & & \\
\hline \multirow[t]{2}{*}{ Fas } & $\mathrm{F}$ & AGTTGGGGAGATGAATGCTG & 171 & 104 & NM_174662 \\
\hline & $\mathrm{R}$ & CCTGTGGATAGGCATGTGTG & & & \\
\hline \multirow[t]{2}{*}{ Haptoglobin } & $\mathrm{F}$ & TGGTCTCCCAGCATAACCTC & 185 & 92 & BC109668 \\
\hline & $\mathrm{R}$ & AGGGTGGAGAACCACCTTCT & & & \\
\hline$C D 62 L$ & $\mathrm{~F}$ & CCGATTGCTGGACTTACCAT & 194 & 93 & NM_174182 \\
\hline
\end{tabular}

${ }^{1}$ The primers for reverse-transcription PCR candidate genes were obtained using Primer3 software and based on bovine sequences obtained from the NCBI database.

${ }^{2}$ CXCL8 = IL-8; CSF-2 = colony stimulating factor- $;$ TNF- $\alpha=$ tumor necrosis factor $\alpha ; M M P-9=$ matrix metallopeptidase-9; $M M P-13=$ matrix metallopeptidase-13; $C C R-5=\mathrm{C}-\mathrm{C}$ chemokine receptor-5; $G R-\alpha=$ glucocorticoid receptor $\alpha ; C D 62 L=\mathrm{L}$-selectin; $A C T B=$ beta-actin; $S D H A=$ succinate dehydrogenase complex subunit A.

blood cell count, hemoglobin concentration, hematocrit percentage, mean corpuscular hemoglobin, and mean corpuscular hemoglobin concentration.

\section{Cortisol and DHEA}

Serum cortisol concentration was higher in lame $(9.84 \pm 0.95 \mathrm{ng} / \mathrm{mL})$ than in sound cows $(6.80 \pm 1.17$ $\mathrm{ng} / \mathrm{mL} ; P \leq 0.05$; Figure 1$)$. Lame cows also had higher serum DHEA levels $(2.35 \pm 0.41 \mathrm{ng} / \mathrm{mL})$ than sound $(1.52 \pm 0.43 \mathrm{ng} / \mathrm{mL} ; P \leq 0.001)$. The cortisol:DHEA ratio was numerically higher in lame $(6.49 \pm 1.43)$ than in sound $(3.68 \pm 1.56)$ cows, but no significant difference was found.

\section{Haptoglobin, Glucose, Protein, Urea, and Creatine Kinase}

Lame cows tended to have higher haptoglobin levels than sound cows $(2.3 \pm 0.2$ vs. $1.8 \pm 0.2 \mathrm{mg} / \mathrm{mL} ; P$ $\leq 0.1)$ as well as tending to have higher glucose levels $(3.13 \pm 0.09$ vs. $2.89 \pm 0.12 \mathrm{mmol} / \mathrm{L} ; P \leq 0.1)$. Protein levels were also higher in lame than sound cows $(89.6 \pm$ 1.2 vs. $84.8 \pm 1.2 \mathrm{~g} / \mathrm{L} ; P \leq 0.01)$. Contrarily, lame cows 
Table 3. Comparison of total leukocyte, neutrophil and lymphocyte number, neutrophil:lymphocyte (N:L) ratio, eosinophil and monocyte number in cows diagnosed with sole ulcers and no other pathology, and sound cows

\begin{tabular}{|c|c|c|c|c|c|c|}
\hline \multirow[b]{2}{*}{ Variable } & \multicolumn{2}{|c|}{ Count $\left(\times 10^{3}\right.$ cells $\left./ \mu \mathrm{L}\right)$} & \multirow[b]{2}{*}{$P$-value } & \multicolumn{2}{|c|}{ Percentage } & \multirow[b]{2}{*}{$P$-value } \\
\hline & Lame & Sound & & Lame & Sound & \\
\hline Total leukocytes & $7.47 \pm 0.55$ & $7.16 \pm 0.55$ & NS & & & \\
\hline Neutrophils & $3.10 \pm 0.29$ & $2.56 \pm 0.29$ & NS & $42.9 \pm 2.8$ & $35.9 \pm 2.8$ & 0.03 \\
\hline Lymphocytes & $5.71 \pm 1.72$ & $5.93 \pm 1.72$ & NS & $42.5 \pm 2.8$ & $48.7 \pm 2.8$ & 0.12 \\
\hline N:L (ratio) & $1.04 \pm 0.10$ & $0.76 \pm 0.10$ & 0.05 & & & \\
\hline Eosinophils & $0.41 \pm 0.04$ & $0.41 \pm 0.04$ & NS & $8.7 \pm 1.8$ & $9.2 \pm 1.8$ & NS \\
\hline Monocytes & $0.68 \pm 0.15$ & $0.68 \pm 0.15$ & NS & $5.9 \pm 0.5$ & $5.9 \pm 0.5$ & NS \\
\hline
\end{tabular}

had lower urea levels than sound $(4.35 \pm 0.27$ vs. 5.17 $\pm 0.26 \mu \mathrm{mol} / \mathrm{L} ; P \leq 0.05)$, and we observed no difference in creatine kinase levels between lame and sound cows $(875.91 \pm 161.07$ vs. $850.03 \pm 159.31 \mu \mathrm{mol} / \mathrm{L})$.

\section{Real-Time RT-qPCR Cytokine Gene Expression}

No difference was observed in expression of IL2, IL4, $I F N-\lambda$, or $T N F-\alpha$ between lame and sound cows. However, sound cows tended to have higher relative expression of the gene coding for colony stimulating factor 2 than lame cows $(1.52 \pm 0.25$ vs. $0.97 \pm 0.25 ; P \leq 0.1)$. In all other cases where differences were detected $(I L$ $1 \alpha: P=0.05 ; I L-1 \beta: P=0.1 ; C X C L 8: P \leq 0.1 ; I L-10$ : $P=0.05)$, relative gene expression in sound cows was, or tended to be, lower than in lame cows (Figure 2).

\section{General Immunological Gene Expression}

No difference was observed in expression of matrix metalloproteinase $(\boldsymbol{M M P})-9$ or chemokine receptor 5

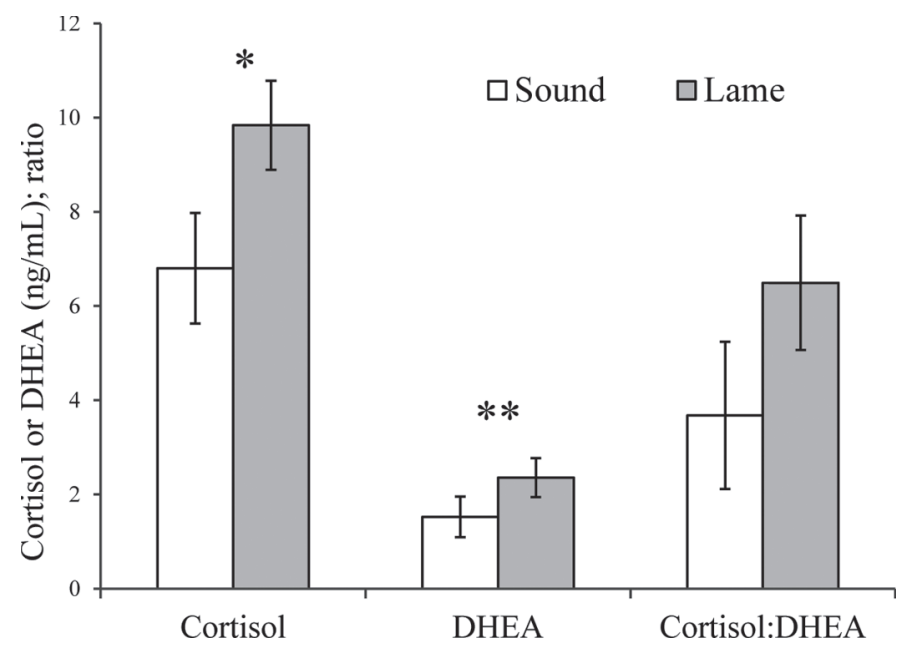

Figure 1. Serum cortisol and dehydroepiandrosterone (DHEA) concentrations in cows that either had an ulcer (lame) or were otherwise healthy (sound). ${ }^{*}$ indicates means differ by $P \leq 0.05$; ** indicates means differ by $P \leq 0.05$
(CCR5). Relative expression of $M M P-13(P \leq 0.01)$, $G R-\alpha(P \leq 0.1)$, Fas $(P \leq 0.05)$, haptoglobin $(P \leq 0.1)$, and CD62L $(P \leq 0.01)$ was, or tended to be, higher in lame than sound cows (Figure 3).

\section{DISCUSSION}

To the authors' knowledge, this study is the first study to describe in detail physiological and immune characteristics of cows that are lame due to presence of sole ulcers but no other pathology compared with otherwise healthy cows. We hypothesized that the pain and stress associated with lameness (Whay et al., 2003) have a negative effect on the systemic immune and inflammatory status of the cow, and thus selected genes for comparison that are differentially expressed in cows that undergo a stressful event, such as parturition or transport (Buckham-Sporer et al., 2008), as well as lame and sound cows (Almeida et al., 2007; O'Driscoll et al., 2009). Thus this study provides novel information about the physiological reaction of the cow to a noninfectious inflammatory health disorder.

Cows with ulcers had higher levels of circulating cortisol than sound cows, and it was outside the normal range for dairy cattle $(4.7-7.6 \mathrm{ng} / \mathrm{mL}$; Radostits et al., 2007). Consideration of leukocyte differential in addition to cortisol level can provide an increasingly reliable insight when considering the state of the animal; the leukocyte response to a stressor occurs over a longer time span than the hormonal response and is hypothesized to be more enduring, and thus indicative not only of immediate, but also of longer term stress (Davis et al., 2008). Although leukocyte numbers were within the normal range for cattle in both cohorts (Kulberg et al., 2002), cows with ulcers had a higher neutrophil percentage, numerically lower lymphocyte percentage, and a higher N:L ratio than sound cows. This type of leukogram is seen in all vertebrate taxa in response to either natural stressors, or administration of stress hormones (Davis et al., 2008). A high N:L ratio has also been described in animals in stressful circumstances (Fell et al., 1999), in cows that are genetically more 


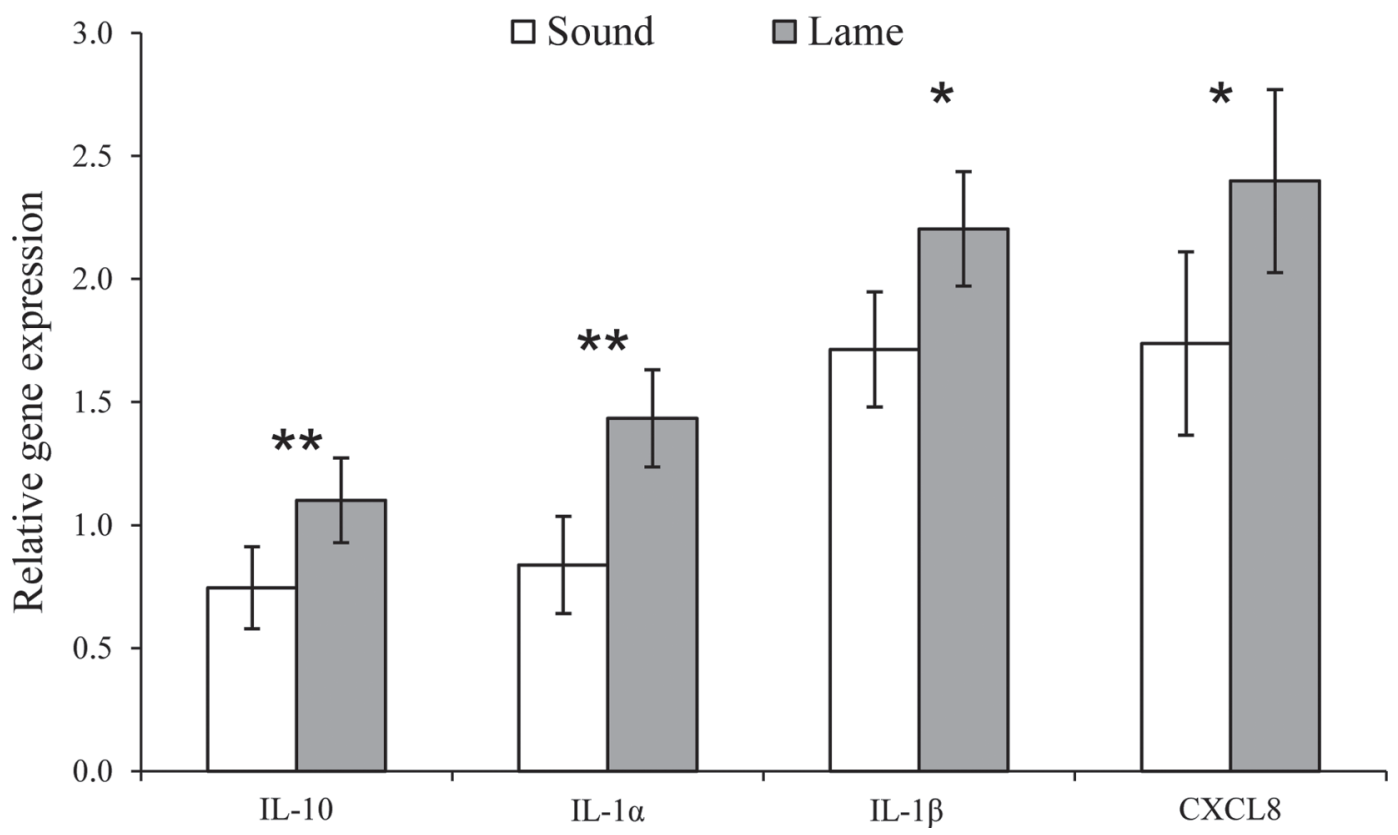

Figure 2. Differences in cytokine relative gene expression in leukocytes of cows that either had an ulcer (lame) or were otherwise healthy (sound). * indicates means differ by $P \leq 0.1,{ }^{* *}$ by $P \leq 0.05$. Values were normalized to reference genes followed by calculation of relative quantities to the highest cycle threshold value.

susceptible to disease (Kulberg et al., 2002), and in cows with poor locomotion (O'Driscoll et al., 2009). Thus, this leukocyte profile is in concordance with the elevated cortisol levels we detected in cows with ulcers.
Contrary to our results, Almeida et al. (2008) reported no significant difference in cortisol levels between lame and sound cows. Yet, in that study, lame cows had cortisol levels that were $49 \%$ higher than sound;

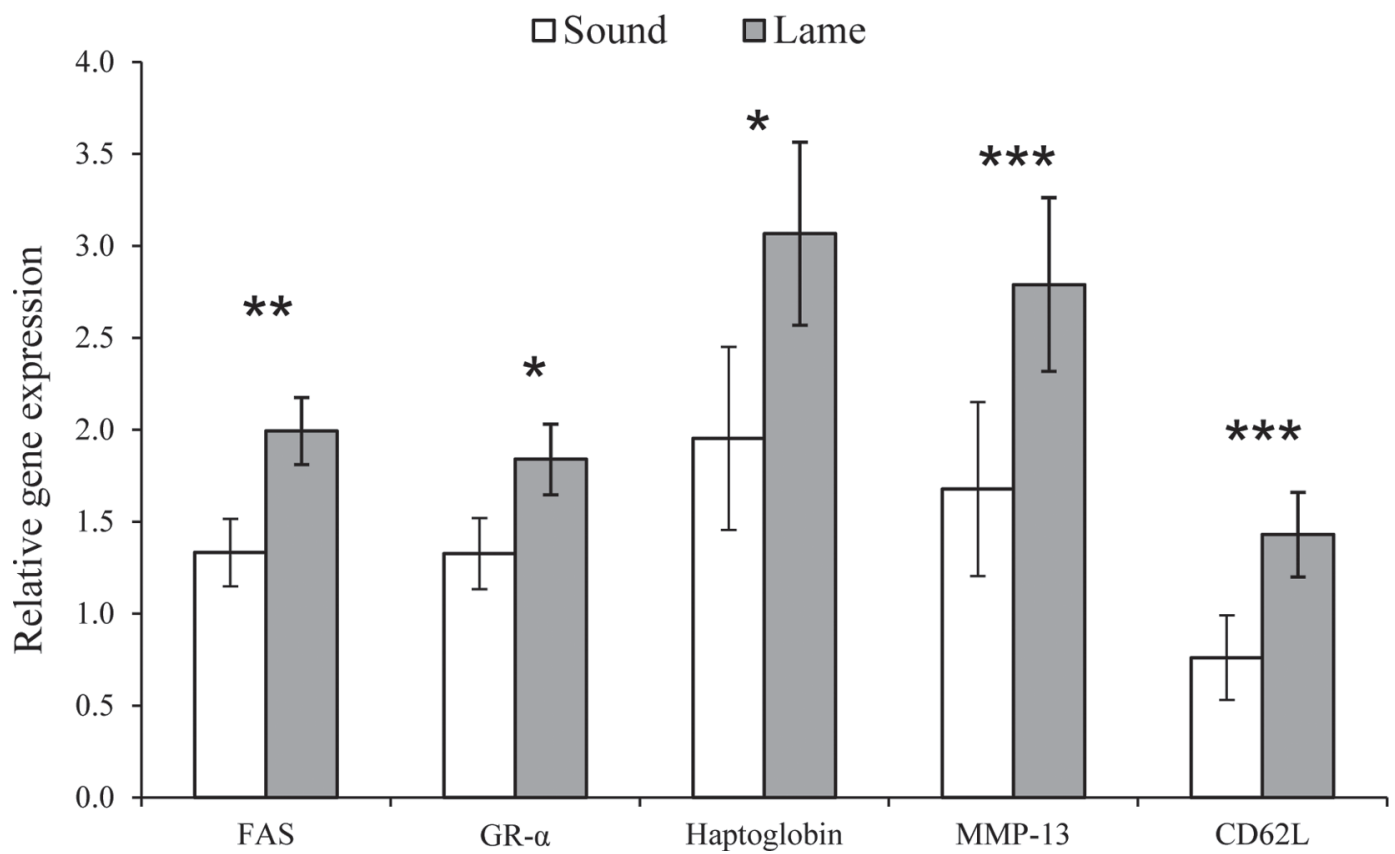

Figure 3. Differences in gene expression in leukocytes of cows that either had an ulcer (lame) or were otherwise healthy (sound). * indicates means differ by $P \leq 0.1,{ }^{* *}$ by $P \leq 0.05,{ }^{* * *}$ by $P \leq 0.01$. Values were normalized to reference genes followed by calculation of relative quantities to the highest cycle threshold value. 
the smaller sample size than in our study may have precluded detection of a significant difference. Although in that study lame cows had lower DHEA levels than sound cows, and we found the opposite, both studies found that cortisol:DHEA ratio was higher in lame than sound cows (although not significant in ours). Thus, cortisol:DHEA ratio could yet prove to be a useful indicator of inflammatory hoof disorders. Further work could investigate the usefulness of this indicator in cows with other foot disorders, and at different stages of inflammation.

Haptoglobin is an acute phase protein. In cattle, serum haptoglobin concentration increases in cases of acute, subacute, and chronic inflammation (Alsemgeest et al., 1994). It is elevated in cows with all levels of lameness, from mild to severe, compared with sound cows (Jawor et al., 2008; Smith et al., 2010; Tadich et al., 2013). Thus it is unsurprising that lame cows tended to have higher levels of both circulating haptoglobin and haptoglobin mRNA expression, and our study confirms that elevated haptoglobin levels appear to be a reliable measure of lameness-associated inflammation. To our knowledge, this is the first study to investigate both haptoglobin levels and associated mRNA expression in lame cows. Cooray et al. (2007) reported that bovine granulocytes contain abundant amounts of haptoglobin in healthy cattle. Thus, it is likely that the increased percentage of neutrophils in lame cows in this study could be related to the tendency for higher levels of both serum haptoglobin and haptoglobin mRNA expression in these animals.

Jawor et al. (2008) reported that clinically lame cows had numerically higher total serum protein levels than healthy cows, and that the protein decreased as lesions healed. This was mainly due to high levels of $\alpha$ - and $\gamma$-globulins, and low levels of albumin, compared with healthy cows. Haptoglobin is an $\alpha$-globulin, and thus the tendency for higher serum haptoglobin levels in lame cows than sound cows in this study likely contributed to the higher total serum protein. It could be useful in future studies to investigate in more detail the makeup of total serum protein in lame animals to understand further the pathophysiology of the disorder.

Although little information is available regarding glucose levels in lame cows, Lischer et al. (2001) found elevated levels of glucose in one-third of cows affected by sole ulcers. One of the metabolic responses to stress is hyperglycemia, due to the release of liver glycogen as a result of injury or sepsis (Weissman, 1990). Moreover, an increase in serum glucose concentration is often attributed to glycogenolysis, which is associated with increased catecholamines and glucocorticoid secretion at the onset of a stressor (McDowell, 1983). Thus an elevated serum cortisol concentration, as well as the pres- ence of an ulcer, could have caused the higher serum glucose levels. Likewise, although we could not find any data pertaining to serum urea concentrations in lame dairy cows, serum urea levels have been observed to be lower in sheep and beef cattle that are submitted to stressors such as isolation, restraint, and transportation (Galyean et al., 1981; Apple et al., 1993).

The primary cause of sole ulcers is displacement of the third phalanx (pedal bone) within the claw capsule, and the resultant concussive forces (Lischer et al., 2002; Bicalho and Oikonomou, 2013). This usually occurs as a result of loosening of the collagen in the hoof around the time of parturition, aggravated by management factors (e.g., concrete flooring) (Bicalho and Oikonomou, 2013). The digital cushion provides a protective layer between the pedal bone and the horn-producing cells (Bicalho and Oikonomou, 2013), and a reduction in its thickness is also implicated in sole ulcer development (Bicalho et al., 2009). Thus, sole ulcers develop under sterile conditions. Even in sterile conditions, a tissue injury can cause cellular necrosis. This can stimulate an innate immune response (Rider et al., 2011), including recruitment of neutrophils and macrophages and production of cytokines and chemokines (Chen and Nunez, 2010).

We selected our references genes for this study on the basis of a previously executed candidate reference gene validation study from our group (O'Loughlin et al., 2011). In that study the same tissue was used (bovine leukocytes) as in the current one, and a comparison was also being made between healthy control animals, and animals which underwent a sterile stress/inflammatory response (i.e., expected activation of the immune system without being exposed to an infectious agent), which is why we considered the genes to be appropriate. Under normal circumstances, a reference gene validation study should include 8 to 10 genes, to ensure accurate and reliable results, and thus the fact that we only investigated 3 can be considered a limitation to our study. Nevertheless, the M-values for our selected reference genes were well within an acceptable range (average M-values in the $0.5-1$ range are expected when evaluating candidate reference targets on a heterogeneous set of samples; Hellemans and Vandesompele, 2014), and our use of the geometric mean of the 3 reference genes improves the reliability of the normalization of the data (Derveaux et al., 2010).

Cytokines are small proteins made and released by cells of the immune system that affect the behavior of other cells (Janeway et al., 2005). They can be either pro- or anti-inflammatory. This study investigated expression of several genes coding for cytokines, as well as genes associated with a more generalized immune and stress response. We detected differences in mRNA 
expression between lame and sound cows for both pro- and anti-inflammatory cytokines; lame cows had greater expression of the pro-inflammatory cytokines IL- $1 \alpha$, and tended to have greater expression of $I L$ $1 \beta$ and $C X C L 8$ mRNA, as well as greater mRNA expression of the anti-inflammatory cytokine IL-10, and tended to have less expression of the pro-inflammatory cytokine CSF-2. This indicates probable regulation of an innate immune response to a sole ulcer (Opal and DePalo, 2000).

Both IL-1 $\alpha$ and IL-1 $\beta$, which were more highly expressed in leukocytes of lame cows, are involved in the initiation of a sterile inflammatory response (Rider et al., 2011). Thus, these cytokines could be implicated in a specific response to sole ulcers. In turn, IL-1 $\beta$ can increase expression of $C X C L 8 \mathrm{mRNA}$ in leukocytes (Fujishima et al., 1993), and both IL-1 $\beta$ and CXCL8 are implicated in activating haptoglobin secretion (Godson et al., 1995; Wigmore et al., 1997). This is in agreement with the tendency for higher serum haptoglobin, CXCL8 mRNA, and haptoglobin mRNA expression in the lame cows in this study. In stressful situations, CXCL8 mRNA is upregulated in bovine leukocytes, and is hypothesized to contribute to neutrophilia (Buckham Sporer et al., 2008; O'Loughlin et al., 2011). Thus stress associated with sole ulcers could have contributed to the tendency for higher CXCL8 expression, and the higher neutrophil percentage in lame cows. It is worth noting however, that several of the differences we detected in gene expression were tendencies, and that gene expression may not correlate to expression of the actual protein. Future work could investigate presence of the gene product.

Lame cows also had greater expression of the antiinflammatory cytokine IL-10, and tended to have less expression of CSF-2, which is pro-inflammatory. Likewise, Almeida et al. (2007) reported that $I L-10$ mRNA was upregulated in the leukocytes of lame cows compared with sound cows, and concluded that this could be indicative of an anti-inflammatory response that has a role in reducing tissue damage and pain. Interleukin-10 is also involved in regulation of keratinocytes (Moore et al., 2001), which could be significant in development of sole ulcers, as hoof horn is produced through keratinization of epidermal cells (Tomlinson et al., 2004).

In the few studies that have investigated differences in leukocyte gene expression in lame and sound cows, $M M P-13$ is consistently identified as being differentially expressed. Not only has $M M P-13$ mRNA been observed to be upregulated in the leukocytes of clinically lame cows, when using both a micro-array and targeted gene expression approach (Almeida et al., 2007), but O'Driscoll et al. (2009) also found that even in cows that were not clinically lame, but with impaired locomotion, leukocyte $M M P-13$ mRNA was upregulated. Matrix metalloproteinases are involved in extracellular protein degradation, with MMP-13 also known as collagenase 3, due to its role in collagen degradation (Entrezgene, 2013). It is possible that MMP-13 plays a role in degradation of the collagen fibers of the suspensory apparatus within the hoof, which could lead to displacement and sinking of the pedal bone, and as a consequence the tissue necrosis that ultimately results in sole ulcers (Lischer et al., 2002). The MMP-13 also has a role in the activation of other MMP such as MMP-2 and MMP-9, which could cause further damage (Leeman et al., 2002). A major cytokine that is associated with MMP-13 secretion is IL-1, so the increased expression of $I L-1 \alpha$ and $I L-1 \beta$ in cows with ulcers could be linked to its production. Thus, any increase in expression of $M M P-13$ may not have been the root cause of sole ulceration, but rather a result of the inflammatory process.

The GR $\alpha$ mRNA is abundantly expressed in neutrophils, yet downregulated by glucocorticoids (Preisler et al., 2000; Burton et al., 2005). However, we found that even though lame cows had elevated cortisol levels compared with sound, they did not have lower expression levels of GR $\alpha$ mRNA. In fact, Buckham-Sporer et al. (2007) and O'Loughlin et al. (2011) found increased expression of $G R \alpha$ mRNA along with a surge in cortisol concentration after exposure to stress. It is possible that the higher neutrophil percentage in lame than sound cows offset any drop in expression by individual cells.

Similar to the work by O'Loughlin et al. (2011), we found a significant increase in expression of CD62L (L-selectin) in cows that were in the stressed (lame) cohort. L-Selectin is a cell adhesion molecule and is involved in migration of neutrophils to sites of inflammation (Kansas, 1996). However, CD62L mRNA expression was downregulated in neutrophils when cattle were exposed to a glucocorticoid challenge test, and this downregulation correlates with peak neutrophilia (Weber et al., 2001). The neutrophilia was hypothesized to occur because CD62L is necessary for cells to migrate to peripheral tissues, and without its expression neutrophils accumulated in circulation. On the other hand, O'Loughlin et al. (2011) found that CD62L expression was higher in leukocytes of stressed animals, and Buckham-Sporer et al. (2007) found that an initial decrease in neutrophil CD62L expression after transportation was followed by a surge in expression after $9 \mathrm{~h}$. These authors hypothesized that after the initial drop in expression, a rebound increase occurs as a result of young neutrophils being released from bone marrow. Chao et al. (1997) also identified a triphasic pattern to CD62L mRNA after activation of 
T-cells, with an initial decrease, followed by an increase due to increased message stability, and a final loss of expression. Thus it is possible that our sampling time coincided with a surge in expression of CD62L after the initial inflammation.

The Fas gene encodes a transmembrane receptor protein, which is an apoptosis promoter (Nagata and Golstein, 1995). The finding that Fas mRNA expression levels were higher in lame cows than sound was surprising, because it has been suggested that depressed Fas expression could be a common scenario that contributes to neutrophilia and neutrophil longevity (Burton et al., 2005; Buckham-Sporer et al., 2007). However, O'Loughlin et al. (2011) found that leukocyte Fas mRNA expression was increased in animals that were exposed to weaning stress, and suggested that its expression could be an immunological attempt to restore homeostasis. It is possible that contrary to being associated with neutrophil percentage, in chronically stressful situations, Fas expression could be related to the reduction of lymphocyte numbers, and contributes to the immunosuppression associated with chronic stress (Shi et al., 2003). Indeed, increased Fas expression is also associated with oxidative stress and several chronic autoimmune disorders (e.g., rheumatoid arthritis, Aggarwal et al., 2013; diabetes, Arya et al., 2011). Thus, it is possible that rather than acting upon neutrophils, in the case of a sterile inflammatory condition such as solar ulceration, elevated Fas mRNA expression is related to lymphocyte apoptosis, and thus a contributing factor to the high N:L ratio.

\section{CONCLUSIONS}

This study provides novel information on the systemic effects of sole ulcers on the dairy cow. The data indicate activation of the immune system, as well as a generalized stress response. Further work to investigate expression of the protein products of differentially expressed genes will provide more insight into pathogenesis of solar ulceration. In particular, the identification of increased expression of MMP13 mRNA in cows with sole ulcers adds to a growing body of evidence implicating increased expression of this gene in cows with impaired locomotion.

\section{ACKNOWLEDGMENTS}

The authors gratefully acknowledge the assistance of John Paul Murphy and Aidan Brennan (Teagasc, Moorepark, Ireland) for their assistance in screening animals for inclusion in the study, and Margaret Murray (Teagasc, Grange, Ireland) for hematology analysis. This study was funded by a Marie Curie Intra-Europe- an Fellowship (FP7-People 2009-IEF; grant agreement number: 252611) to Keelin O'Driscoll.

\section{REFERENCES}

Aggarwal, A., A. Sharma, and A. Bhatnagar. 2013. Bi(o)communications among peripheral blood fractions: A focus on NK and NKT cell biology in rheumatoid arthritis. Autoimmunity 46:238-250.

Almeida, P. E., P. S. D. Weber, J. L. Burton, R. J. Tempelman, J. P. Steiber, and A. J. Zanella. 2007. Gene expression profiling of peripheral mononuclear cells in lame dairy cows with foot lesions. Vet. Immunol. Immunopathol. 120:234-245.

Almeida, P. E., P. S. D. Weber, J. L. Burton, and A. J. Zanella. 2008. Depressed DHEA and increased sickness response behaviors in lame dairy cows with inflammatory foot lesions. Domest. Anim. Endocrinol. 34:89-99.

Alsemgeest, S. P. M., H. C. Kalsbeek, Th. Wensing, J. P. Koeman, A. M. van Ederen, and E. Gruys. 1994. Concentrations of serum amyloid-A (SAA) and haptoglobin ( $\mathrm{Hp})$ as parameters of inflammatory diseases in cattle. Vet. Q. 16:21-23.

Apple, J. K., J. E. Minton, K. M. Parsons, and J. A. Unruh. 1993. Influence of repeated restraint and isolation stress and electrolyte administration on pituitary-adrenal secretions, electrolytes, and other blood constituents of sheep. J. Anim. Sci. 71:71-77.

Arya, A. K., P. Deepa, and T. Kamlakar. 2011. Relationship between oxidative stress and apoptotic markers in lymphocytes of diabetic patients with chronic non-healing wound. Diabetes Res. Clin. Pract. 94:377-384.

Bicalho, R. C., V. S. Machado, and L. S. Caixeta. 2009. Lameness in dairy cattle: A debilitating disease or a disease of debilitated cattle? A cross-sectional study of lameness prevalence and thickness of the digital cushion. J. Dairy Sci. 92:3175-3184.

Bicalho, R. C., and G. Oikonomou. 2013. Control and prevention of lameness associated with claw lesions in dairy cows. Livest. Sci. 156:96-105.

Bleavins, M. R., C. Carini, M. Jurima-Romet, and R. Rahbari, ed. 2011. Biomarkers in Drug Development: A Handbook of Practice Application, and Strategy. John Wiley and Sons, Hoboken, NJ.

Buckham-Sporer, K., L. Xaio, R. J. Tempelman, J. L. Burton, B. Earley, and M. A. Crowe. 2008. Transportation stress alters the circulating steroid environment and neutrophil gene expression in beef bulls. Vet. Immunol. Immunopathol. 121:300-320.

Buckham Sporer, K. R., J. L. Burton, B. Earley, and M. A. Crowe. 2007. Transportation stress in young bulls alters expression of neutrophil genes important for the regulation of apoptosis, tissue remodeling, margination, and antibacterial function. Vet. Immunol. Immunopathol. 118:19-29.

Burton, J. L., S. A. Madsen, L.-C. Chang, P. S. D. Weber, K. R. Buckham, R. van Dorp, M.-C. Hickey, and B. Earley. 2005. Gene expression signatures in neutrophils exposed to glucocorticoids: A new paradigm to help explain "neutrophil dysfunction" in parturient dairy cows. Vet. Immunol. Immunopathol. 105:197-219.

Chao, C. C., R. Jensen, and M. O'Dailey. 1997. Mechanisms of L-selectin regulation by activated T-cells. J. Immunol. 159:1686-1694.

Chen, G. Y., and G. Nunez. 2010. Sterile inflammation: Sensing and reacting to damage. Natl. Rev. 10:826-837.

Cooray, R., K. P. Waller, and P. Venge. 2007. Haptoglobin comprises about $10 \%$ of granule protein extracted from bovine granulocytes isolated from healthy cattle. Vet. Immunol. Immunopathol. 119:310-315.

Davis, A. K., D. L. Maney, and J. C. Maerz. 2008. The use of leukocyte profiles to measure stress in vertebrates: A review for ecologists. Funct. Ecol. 22:760-772.

Derveaux, S., J. Vandesompele, and J. Hellemans. 2010. How to do successful gene expression analysis using real-time PCR. Methods 50:227-230.

EFSA (European Food Safety Authority). 2009. Scientific report of EFSA prepared by the Animal Health and Animal Welfare Unit on the effects of farming systems on dairy cow welfare and disease. Annex to the EFSA Journal 1143:1-7. 
Entrez Gene. 2013. MMP13 matrix metallopeptidase 13 (collagenase 3). Accessed Jan. 7, 2013. http://www.ncbi.nlm.nih.gov/gene?Db $=$ gene $\&$ Cmd $=$ ShowDetailView $\&$ TermToSearch $=4322$.

Fell, L. R., I. G. Colditz, K. H. Walker, and D. L. Watson. 1999. Associations between temperament, performance and immune function in cattle entering a commercial feedlot. Aust. J. Exp. Agric. 39:795-802.

Fujishima, S., A. R. Hoffman, T. Vu, K. J. Kim, H. Zheng, D. Daniel, Y. Kim, E. F. Wallace, J. W. Larrick, and T. A. Raffin. 1993. Regulation of neutrophil interleukin 8 gene expression and protein secretion by LPS, TNF- $\alpha$, and IL-13. J. Cell. Physiol. 154:478-485.

Galyean, M. L., R. W. Lee, and M. E. Hubbert. 1981. Influence of fasting and transit on ruminal and blood metabolites in beef steers. J. Anim. Sci. 53:7-18.

Godson, D. L., M. E. Baca-Estrada, A. G. Van Kessel, H. P. A. Hughes, M. A. Morsy, J. Van Donkersgoed, R. J. Harland, D. E. Shuster, M. J. Daley, and L. A. Babiuk. 1995. Regulation of bovine acute phase responses by recombinant interleukin-1ß. Can. J. Vet. Res. 59:249-255.

Hart, B. L. 1988. Biological basis of the behavior of sick animals. Neurosci. Biobehav. Rev. 12:123-137.

Hellemans, J., and J. Vandesompele. 2014. Selection of reliable reference genes for RT-qPCR analysis. Methods Mol. Biol. 1160:19-26.

Janeway, C. R., P. Travers, M. Walport, and M. J. Shlomchik. 2005. Immunobiology. The Immune System in Health and Disease. 6th ed. Garland Science Publishing, New York, NY.

Jawor, P., S. Steiner, T. Stefaniak, W. Baumgartner, and A. Rzasa. 2008. Determination of selected acute phase proteins during the treatment of limb diseases in dairy cows. Vet Med-Czech. $53: 173-183$.

Kansas, G. S. 1996. Selectins and their ligands: Current concepts and controversies. Blood 88:3259-3287.

Knott, L., J. Tarlton, H. Craft, and A. J. F. Webster. 2007. Effects of housing, parturition and diet change on the biochemistry and biomechanics of the support structures of the hoof of dairy heifers. Vet. J. 174:277-287.

Kossaibati, M., and R. Esslemont. 1997. The costs of production diseases in dairy herds in England. Vet. J. 154:41-51.

Kulberg, S., A. K. Storset, B. Heringstad, and H. J. S. Larsen. 2002. Reduced levels of total leukocytes and neutrophils in Norwegian cattle selected for decreased mastitis incidence. J. Dairy Sci. 85:3470-3475.

Leeman, M. F., S. Curran, and G. Murray. 2002. The structure, regulation, and function of human matrix metalloproteinase-13. Crit. Rev. Biochem. Mol. Biol. 37:149-166.

Lischer, C. J., A. Dietrich-Hunkeler, H. Geyer, J. Schulze, and P. Ossent. 2001. Healing process of uncomplicated sole ulcers in dairy cows kept in tie stalls: Clinical description and blood chemical investigations. Schweiz. Arch. Tierheilkd. 143:125-133.

Lischer, C. J., P. Ossent, M. Raber, and H. Geyer. 2002. Suspensory structures and supporting tissues of the third phalanx of cows and their relevance to the development of typical sole ulcers (Rusterholz ulcers). Vet. Rec. 151:694-698.

McDowell, G. H. 1983. Hormonal control of glucose homeostasis in ruminants. Proc. Nutr. Soc. 42:149-167.

Moore, K. W., R. De Waal Malefyt, R. L. Coffman, and A. O'Garra. 2001. Interleukin-10 and the interleukin-10 receptor. Annu. Rev. Immunol. 19:683-765.

Murray, R. D., D. Y. Downham, M. J. Clarkson, W. B. Faull, J. W. Hughes, F. J. Manson, J. B. Merrit, W. B. Russel, J. E. Sutherst, and W. R. Ward. 1996. Epidemiology of lameness in dairy cattle: Description and analysis of foot lesions. Vet. Rec. 138:586-591.

Nagata, S., and P. Golstein. 1995. The Fas death factor. Science 267:1449-1456.

Nocek, J. E. 1997. Bovine acidosis: Implications on laminitis. J. Dairy Sci. 80:1005-1028.

O'Driscoll, K., L. Boyle, P. French, and A. Hanlon. 2008. The effect of out-wintering pad design on hoof health and locomotion score of dairy cows. J. Dairy Sci. 91:544-553.
O'Driscoll, K., B. O'Brien, D. Gleeson, and L. Boyle. 2010. Effect of milking frequency and nutritional level on hoof health, locomotion score and lying behaviour of dairy cows . Livest. Sci. 127:248-256.

O'Driscoll, K. K. M., A. C. Lossie, M. M. Schutz, and S. D. Eicher. 2009. The effect of floor surface on dairy cow immune function and locomotion score. J. Dairy Sci. 92:4249-4261.

O'Loughlin, A., M. McGee, S. M. Waters, S. Doyle, and B. Earley. 2011. Examination of the bovine leukocyte environment using immunogenic biomarkers to assess immunocompetence following exposure to weaning stress. BMC Vet. Res. 7:45.

Opal, S. M., and V. A. DePalo. 2000. Anti-inflammatory cytokines. Chest 117:1162-1172

Preisler, M. T., P. S. D. Weber, R. J. Tempelman, R. J. Erskine, H. Hunt, and J. L. Burton. 2000. Glucocorticoid receptor downregulation in neutrophils of periparturient cows. Am. J. Vet. Res. 61:14-19.

Radostits, O. M., C. C. Gay, K. W. Hinchcliff, and P. D. Constable. 2007. Veterinary Medicine. Saunders-Elsevier, Philadelphia, PA.

Rider, P., Y. Carmi, O. Guttman, A. Braiman, I. Cohen, E. Voronov M. R. White, C. A. Dinarello, and R. N. Apte. 2011. IL-1 $\alpha$ and IL-1 $\beta$ recruit different myeloid cells and promote different stages of sterile inflammation. J. Immunol. 187:4835-4843.

Shi, Y., S. Devadas, K. M. Greeneltch, D. Yin, R. A. Mufson, and J. Zhou. 2003. Stressed to death: Implication of lymphocyte apoptosis for psychoneuroimmunology. Brain Behav. Immun. 17:S18S26

Smith, B. I., J. Kauffold, and L. Sherman. 2010. Serum haptoglobin concentrations in dairy cattle with lameness due to claw disorders. Vet. J. 186:162-165

Tadich, N., S. Bastias, C. Rosenfeld, and L. E. Green. 2013. Nociceptive threshold, blood constituents and physiological values in 213 cows with locomotion scores ranging from normal to severely lame. Vet. J. 197:401-405.

Tarlton, J. F., D. E. Holah, K. M. Evans, S. Jones, G. R. Pearson, and A. J. F. Webster. 2002. Biomechanical and histopathological changes in the support structures of bovine hooves around the time of first calving. Vet. J. 163:196-204.

Thoefner, M. B., O. Wattle, C. C. Pollitt, K. R. French, and S. S. Nielsen. 2005. Histopathology of oligofructose-induced acute laminitis in heifers. J. Dairy Sci. 88:2774-2782.

Tomlinson, D. J., C. H. Mulling, and T. M. Fakler. 2004. Invited review: Formation of keratins in the bovine claw: Roles of hormones, minerals, and vitamins in functional claw integrity. J. Dairy Sci. 87:797-809.

Watkins, L. R., and S. F. Maier. 1999. Implications of immune-tobrain communications for sickness and pain. Proc. Natl. Acad. Sci. USA 96:7710-7713.

Weber, P. S. D., S. A. Madsen, G. W. Smith, J. J. Ireland, and J. L. Burton. 2001. Pre-translational regulation of neutrophil L-selectin in glucocorticoid-challenged cattle. Vet. Immunol. Immunopathol. 83:213-240.

Weber, P. S. D., S. A. Madsen-Bouterse, G. J. M. Rosa, S. S. Sipkovsky, X. Ren, P. E. Almeida, R. Kruska, R. G. Halgren, J. L. Barrick, and J. L. Burton. 2006. Analysis of the bovine neutrophil transcriptome during glucocorticoid treatment. Physiol. Genomics 28:97-112.

Weissman, C. 1990. Review article: The metabolic response to stress: An overview and update. Anesthesiology 73:308-327.

Whay, H. R., D. C. J. Main, L. E. Green, and A. J. F. Webster. 2003. Assessment of the Welfare of Dairy Cattle using animalbased measurements: Direct observations and investigation of farm records. Vet. Rec. 153:197-202.

Whay, H. R., A. E. Watermann, and A. J. Webster. 1997. Association between locomotion, claw lesions and nociceptive threshold in dairy heifers during the prepartum period. Vet. J. 154:155-161.

Wigmore, S. J., K. C. Faron, J. P. Maingay, P. B. Lai, and J. A. Ross. 1997. Interleukin- 8 can mediate acute-phase protein production by isolated human hepatocytes. Am. J. Physiol. 273:E720-E726. 